\title{
Murine neuroblastoma cell lines developed by conditional reprogramming preserve heterogeneous phenotypes observed in vivo
}

\author{
Ewa Krawczyk ${ }^{1}$ - Sung-Hyeok Hong ${ }^{2}$ - Susana Galli ${ }^{2}$ - Emily Trinh $^{2}$ - Larissa Wietlisbach ${ }^{2}$ - Sara F. Misiukiewicz ${ }^{3}$ \\ Jason U. Tilan ${ }^{3} \cdot$ You-Shin Chen $^{2} \cdot$ Richard Schlegel $^{1} \cdot$ Joanna Kitlinska $^{2}$
}

Received: 6 December 2018 / Revised: 14 June 2019 / Accepted: 20 June 2019 / Published online: 13 August 2019

(c) United States \& Canadian Academy of Pathology 2019

\begin{abstract}
Neuroblastoma (NB) is a pediatric tumor of the peripheral nervous system. Treatment of the disease represents an unsolved clinical problem, as survival of patients with aggressive form of NB remains below 50\%. Despite recent identification of numerous potential therapeutic targets, clinical trials validating them are challenging due to the rarity of the disease and its high patient-to-patient heterogeneity. Hence, there is a need for the accurate preclinical models that would allow testing novel therapeutic approaches and prioritizing the clinical studies, preferentially in personalized way. Here, we propose using conditional reprogramming (CR) technology for rapid development of primary NB cell cultures that could become a new model for such tests. This newly established method allowed for indefinite propagation of normal and tumor cells of epithelial origin in an undifferentiated state by their culture in the presence of Rho-associated kinase (ROCK) inhibitor, Y27632, and irradiated mouse feeder cells. Using a modification of this approach, we isolated cell lines from tumors arising in the TH-MYCN murine transgenic model of NB (CR-NB). The cells were positive for neuronal markers, including Phox2B and peripherin and consisted of two distinct populations: mesenchymal and adrenergic expressing corresponding markers of their specific lineage. This heterogeneity of the CR-NB cells mimicked the different tumor cell phenotypes in TH-MYCN tumor tissues. The CR-NB cells preserved anchorage-independent growth capability and were successfully passaged, frozen and biobanked. Further studies are required to determine the utility of this method for isolation of human NB cultures, which can become a novel model for basic, translational, and clinical research, including individualized drug testing.
\end{abstract}

\section{Introduction}

Neuroblastoma (NB) is a rare malignant disease of autonomic nervous system $[1,2]$. It is the most common type of pediatric cancer diagnosed during the first year of life. The median age of diagnosis is 17 months. NBs arise from precursors of sympathetic neurons, most commonly in

$\triangle$ Ewa Krawczyk

Ewa.Krawczyk@georgetown.edu

1 Center for Cell Reprogramming, Georgetown University Medical Center, Washington DC, USA

2 Department of Biochemistry and Molecular \& Cellular Biology, Georgetown University Medical Center, Washington DC, USA

3 Human Science Department, School of Nursing and Health Studies, Georgetown University Medical Center, Washington DC, USA adrenal gland, but also in peripheral sympathetic ganglia $[1,2]$. These tumors vary in their differentiation levels and clinical presentation, ranging from spontaneously regressing disseminated disease, through curable localized lesions, to aggressive metastatic malignancies [3, 4]. Treatment of the high risk NB remains an unsolved clinical problem. Despite multimodal therapies, the survival for these patients remains below $50 \%$ and there is no efficient treatment for the recurrent disease [2, 5].

As with other pediatric tumors, NB has a relatively low number of genetic aberrations, compared with the adult cancers $[1,3,6,7]$. However, these genetic lesions are also heterogeneous and do not always correlate directly with the disease phenotype and its clinical outcome. Moreover, recent studies indicate that the recurrent tumors are genetically and phenotypically different from the tumors at diagnosis, which thus far serve as a basis for the disease stratification and treatment decisions $[6,7]$. Hence, performing additional biopsies of the recurrent 
tumors or analysis of the circulating tumor cells have been proposed to enable additional molecular profiling during disease progression [5].

Although basic science research on NB is rapidly progressing, translating novel findings to the clinic is challenging. Despite recent identification of many potential therapeutic targets, clinical trials are limited by small number of NB patients [5]. Thus, significant consideration needs to be given to prioritizing such trials and identifying the most promising targets. Therefore, establishing reliable preclinical models of NB are of utmost importance. Given the disease heterogeneity, models that accurately recapitulate disease phenotype of the particular patient would allow for personalized treatment decisions.

Current NB research relies mainly on established cell lines, mostly developed from highly aggressive tumors [8]. While the use of these cell lines has contributed to many discoveries in the NB field, the continuous culture in vitro may contribute to accumulation of new genetic aberrations. Moreover, the conventional cell lines may not fully retain the complexity and heterogeneity of primary cancers in patients and therefore might not be ideal for predicting the efficacy of investigational drugs in experimental and preclinical settings [9-11]. Nevertheless, some aspects of intratumoral heterogeneity can be tested in these cell lines. For example, recent studies indicated the presence of two interchangeable NB cell populations-adrenergic cells with neuronal phenotype and high proliferation rates and undifferentiated mesenchymal cells with migratory and invasive properties [12]. These findings were subsequently validated in patients' samples [13, 14]. However, although valuable, these cell lines do not reflect patient-to-patient variability of the disease. Thus, methods allowing for fast and effective development of cell cultures from individual NB patients with tumors of various phenotypes would be a valuable tool for personalized testing of targeted therapies.

Among animal models of NB, the tyrosine hydroxylase (TH)-MYCN transgenic mice are currently the most widely used for preclinical research on NB [8, 15]. These mice express human MYCN oncogene under control of the rat $\mathrm{TH}$ promoter, directing its expression to sympathetic neurons. This genetic aberration mimics MYCN amplification present in the most aggressive cases of NB and triggers formation of tumors in peripheral sympathetic ganglia [15-17]. These tumors show many properties of the human NB, including histopathological features, genetic profile and mRNA expression patterns [18-20]. However, the direct use of this model for preclinical studies is challenging due to relatively low tumor frequency ( $33 \%$ in hemizygous mice), long time to NB development and problems with animal breeding of the mouse strain used $[8,15]$.

To overcome the above limitations associated with traditional NB models, we tested the utility of a recently developed conditional reprogramming (CR) technology to develop primary cell cultures from NB tumors [21]. This technology, an epitome of personalized medicine, is currently considered to be a highly significant advance in patient-derived cancer models [22-25]. CR allows establishing cell lines from tumors and normal tissues and growing them indefinitely without genetic alterations [26]. The induction of CR is rapid and results from reprogramming of the whole cell population rather than clonal selection. Importantly, this effect is reversible, as the cells differentiate to their original phenotype after removing $\mathrm{CR}$ factors [27]. CR induces cancer cells to grow at a rapid rate while retaining their tumorigenic properties and characteristic genetic features [28]. Overall, CR has been very successful in generating human tumor cell cultures derived from epithelial cancers. To our knowledge, this is the first demonstration of the use of this method to develop NB cell lines.

In this study, we have established numerous murine NB cell lines from TH-MYCN mice using CR technology. Our prior attempts to establish such cell lines using traditional cell culture techniques were hindered by neuronal differentiation that precluded cell passaging. In contrast, the $\mathrm{CR}$ cell lines could be continuously grown and biobanked. They preserved cellular heterogeneity observed in NB tumors in vivo, expressed NB biomarkers and had an ability to grow under anchorage-independent conditions. If proven successful in human NB, CR may become an important tool for the rapid generation of patient-derived cell lines that can be subsequently used for testing personalized treatment options, as previously described for adult malignancies.

\section{Materials and methods}

\section{Animal samples}

129X1/SvJ mice expressing the human MYCN oncogene under a rat TH promoter (TH-MYCN mice) were obtained from the National Cancer Institute (Frederick, MD) [15]. The tumors were harvested when they reached the size of $1 \mathrm{~cm}^{3}$. Tissue specimens were collected aseptically into sample collection medium consisting of Dulbecco's modified Eagle medium (DMEM) (Gibco, Gaithersburg, MD) supplemented with 1:100 penicillin/streptomycin mix (Gibco), $10 \mathrm{mg} / \mathrm{ml}$ gentamycin (Gibco), $250 \mu \mathrm{g} / \mathrm{ml}$ amphotericin B (Fisher Scientific, Hampton, NH), $50 \mathrm{mg} / \mathrm{ml}$ nystatin (Sigma-Aldrich, St. Louis, MO), and $10 \mu \mathrm{M}$ ROCK 
inhibitor (Enzo Life Sciences, Farmingdale, NY), and kept at $4{ }^{\circ} \mathrm{C}$, as previously described [21]. The study was approved by the Georgetown University Animal Care and Use Committee.

\section{Tissue processing}

Fresh tissue specimens were processed, as previously described [21]. Briefly, tissue samples were rinsed with 95-100\% ethanol, washed with cold $\left(4^{\circ} \mathrm{C}\right)$ PBS (Gibco) and minced with a scalpel. Tissue fragments were incubated with collagenase IV (Stemcell Technologies, Vancouver, Canada) for $20 \mathrm{~min}$ at $37^{\circ} \mathrm{C}$ on a rocking platform. After enzymatic treatment, cells were centrifuged $(300 \mathrm{~g}, 5 \mathrm{~min}$, $4{ }^{\circ} \mathrm{C}$ ), resuspended in a culture medium and plated.

\section{Cell culture}

Tissue-derived NB cells were subsequently cultured using conventional or $\mathrm{CR}$ cell methods. The conventional culture encompassed incubation in DMEM supplemented with $10 \%$ fetal bovine serum (FBS), 1:100 penicillin/streptomycin mix and $200 \mathrm{mM}$ L-Glutamine (all the above tissue culture supplies obtained from Gibco). The CR culture involved a standard combination of the Swiss-3T3-J2 mouse fibroblasts used as feeder cells and $10 \mu \mathrm{M}$ ROCK inhibitor, Y27632, in the F medium containing DMEM + F12 nutrient mix (Gibco) (3:1 v/v), supplemented with $5 \mu \mathrm{g} / \mathrm{ml}$ insulin (Sigma-Aldrich), $250 \mathrm{ng} / \mathrm{ml}$ amphotericin B (Fisher Scientific), $10 \mu \mathrm{g} / \mathrm{ml}$ gentamicin (Gibco), $0.1 \mathrm{nM}$ cholera toxin (Sigma-Aldrich), $0.125 \mathrm{ng} / \mathrm{ml}$ epidermal growth factor (EGF) (Life Technologies, Carlsbad, CA), and $25 \mathrm{ng} / \mathrm{ml}$ hydrocortisone (Sigma-Aldrich) [21]. Moreover, various modifications of the above method were tested (Table 1). In addition, factors previously implicated in NB were added to the medium: brain-derived neurotropic factor (BDNF) (R\&D Systems, Minneapolis, MN), neuropeptide Y (NPY) (Bachem, Bubendorf, Switzerland) and corticosterone
(Abcam, Cambridge, MA) (Table 1) [29-37]. Cells were cultured at $37^{\circ} \mathrm{C}, 5 \% \mathrm{CO}_{2}$ and 21 or $2 \% \mathrm{O}_{2}$ (HERACELL $150 \mathrm{i}$ variable oxygen control incubator), in non-coated or coated with collagen I (Corning, Corning, NY) cell culture vessels, as previously described [21].

The most optimal growth conditions involved the use of $\mathrm{F}$ medium in combination with Y-27632 compound (FY medium), non-coated vessels, and hypoxic conditions $\left(37^{\circ} \mathrm{C}, 5 \% \mathrm{CO}_{2}, 2 \% \mathrm{O}_{2}\right)$, as highlighted in Table 1. These conditions were subsequently used to establish CRNB cell lines, which were passaged, frozen in cryopreservation medium containing 90\% FBS (Gibco), 10\% dimethyl sulfoxide (DMSO) (Fisher Scientific) and $10 \mu \mathrm{M}$ Y-27632 (Enzo Life Sciences) and biobanked at $-196{ }^{\circ} \mathrm{C}$ (liquid nitrogen freezer) [21]. Growing cells were monitored and phase contrast pictures were taken using EVOS XL digital inverted microscope (Advanced Microscopy Group, Mill Creek, WA). Assessment of cell viability was performed using $0.4 \%$ Trypan Blue stain (Invitrogen, Carlsbad, CA). Cell suspension was mixed 1:1 with Trypan Blue solution and viability was assessed while counting cells with Countess ${ }^{\mathrm{TM}}$ Automated Cell Counter (Invitrogen). To determine ratio of mesenchymal and adrenergic cells, $0.2 \times 10^{6}$ cells were plated and fixed with $4 \%$ paraformaldehyde at $50-70 \%$ confluence. The cells of each type were identified based on the morphological criteria. For each cell line, 100-200 attached cells were counted under microscope, in triplicates and the proportion of both cell types was calculated. The results were validated based on the biomarker expression (NPY and $\mathrm{TH}$ for adrenergic cells, and vimentin for mesenchymal cells).

\section{Immunofluorescence}

Immunofluorescence detection of biomarkers was performed on NB cells grown on $22 \times 22 \mathrm{~mm}$ glass cover slips, fixed in $4 \%$ (w/v) paraformaldehyde $(20 \mathrm{~min})$, permeabilized in PBS
Table 1 NB cell growth conditions. The most optimal growth conditions are highlighted in bold

\begin{tabular}{|c|c|c|c|c|c|c|}
\hline Medium & Y-27632 & $\mathrm{J} 2$ cells & Supplements & $\mathrm{O}_{2}$ & Coating & Growth \\
\hline DMEM & & & & $21 \%$ vs. $2 \%$ & & \pm \\
\hline F medium & + & & & $21 \%$ vs. $\mathbf{2 \%}$ & $\begin{array}{l}\text { Collagen }(+) \text { vs. no } \\
\text { coating }\end{array}$ & $\begin{array}{l}+ \\
++\end{array}$ \\
\hline F medium & + & + & & $21 \%$ vs. $2 \%$ & & - \\
\hline $\mathrm{F}$ medium & & & & $21 \%$ vs. $2 \%$ & & + \\
\hline F medium & + & & $\operatorname{NPY}\left(10^{-7} \mathrm{M}\right)$ & $21 \%$ vs. $2 \%$ & & + \\
\hline F medium & + & & $\mathrm{BDNF}(1 \mathrm{ng} / \mathrm{mL})$ & $21 \%$ vs. $2 \%$ & & + \\
\hline $\mathrm{F}$ medium & + & & Corticosterone $\left(10^{-5} \mathrm{M}\right)$ & $21 \%$ vs. $2 \%$ & & \pm \\
\hline
\end{tabular}

" ++ " indicates that the cells grew to confluence no longer that 10 days before passaging; "+" indicates 10-21 days growth before passaging; " \pm " indicates >21 days growth before passaging; "-" indicates no cell attachment and subsequently no growth 
containing $0.1 \%(\mathrm{w} / \mathrm{v})$ saponin $(10 \mathrm{~min})$ and blocked in Pgel-S $(\mathrm{PBS}+0.2 \%(\mathrm{w} / \mathrm{v})$ gelatin $+0.1 \%$ saponin $)$ containing $10 \%$ normal donkey serum (20 min), as previously described [38]. The following primary antibodies were used: rabbit antiPhox2B (1:100 dilution) (Abcam), rabbit anti-vimentin (1:100) (Cell Signaling Technologies, Danvers, MA), rabbit anti-NPY $(1: 1,000)$ (Cell Signaling Technologies), rabbit antiperipherin (1:750) (Novus Biologicals, Littleton, CO), mouse anti-TH (1:200) (Thermo Fisher Scientific, Waltham, MA), rabbit anti-NPY Y5 receptor (NPY5R, 1:100) (Abcam), and mouse anti-GD2 (1:100) (Santa Cruz Biotechnology, Dallas, TX). Alexa Fluor ${ }^{\circledR}$ 488-, and Alexa Fluor ${ }^{\circledR}$ 594-conjugated donkey secondary antibodies (Molecular Probes, Eugene, OR) were applied at a concentration of $5 \mu \mathrm{g} / \mathrm{ml}$ in Pgel-S for $60 \mathrm{~min}$. Actin filaments were visualized using Alexa Fluor 488 Phalloidin (Molecular Probes) at a concentration of $8 \mathrm{U} / \mathrm{ml}$ in Pgel-S for $20 \mathrm{~min}$. DNA was stained using Hoechst dye 33258 (Sigma-Aldrich) at $0.5 \mu \mathrm{g} / \mathrm{ml}$ in PBS, before mounting in ProLong ${ }^{\circledR}$ mounting medium (Invitrogen). A Zeiss Axioskop microscope was used for visualization and microphotography. Image post processing included adjusting of brightness, contrast, and/or intensity using CorelDRAW ${ }^{\circledR} \mathrm{X} 3$ Graphic Suite (Corel Corporation, Ottawa, Canada) in the same way for all experiments. To outline the periphery of cells, the "local equalization" feature of Corel Photo-Paint X3 (Corel Corporation) was used.

\section{NPY Enzyme-Linked Immunosorbent Assay}

Conditioned media were collected from NB cells upon $24 \mathrm{~h}$ culture. NPY concentration in the media was determined using NPY Enzyme Immunoassay Kit (Bachem Peninsula Laboratories, San Carlos, CA), as previously described [39, 40].

\section{Histological analyses}

Immunohistochemistry was performed on the formalinfixed, paraffin embedded tissue sections from tumors arising in TH-MYCN mice. Antigen retrieval was performed in a pressure cooker containing Target Retrieval Solution, pH 6.10 (Dako Corporation, Carpinteria, CA) for $20 \mathrm{~min}$. The tissue sections were incubated for $1 \mathrm{~h}$ at room temperature with the following rabbit polyclonal antibodies: anti-Phox2B (1:250) (Abcam), anti-NPY (1:1000) (Sigma-Aldrich), anti-vimentin 1:250 (Cell Signaling Technologies), and anti-NPY5R (1:300) (Novus Biologicals), as well as mouse monoclonal antiTH antibody (1:500) (Thermo Scientific), followed by 30 min. incubation with EnVision + System-HRP-AntiRabbit secondary antibody and Liquid DAB + SubstrateChromogen (Dako Corporation). The tissue samples were counterstained with hematoxylin. Negative control slides omitted the primary antibody. The staining pattern was confirmed by a pathologist. We considered immunostaining as positive based on the following subcellular localizations: nuclear for Phox2B, cytoplasmic for NPY and $\mathrm{TH}$, and membrane for NPY5R and vimentin.

\section{Anchorage-independent growth assays}

Poly 2-hydroxyethyl methacrylate (Poly-HEMA) (SigmaAldrich) was used to coat $100 \mathrm{~mm}$ dishes. A total of $4 \mathrm{ml}$ of $20 \mathrm{mg} / \mathrm{ml}$ in $95 \% \mathrm{EtOH}$ solution was added to a plate, dried overnight at $37^{\circ} \mathrm{C}$, and stored at room temperature prior to use. NB cells were plated in FY medium on poly-HEMAcoated $100 \mathrm{~mm}$ dishes $\left(3.5 \times 10^{5}\right.$ cells per dish). Alternatively, they were resuspended in $15 \mathrm{ml}$ tubes containing 1:2 mix of FY medium and methylcellulose stock solution (R\&D Systems), $1 \times 10^{5}$ cells per tube. Poly-HEMA dishes and tubes with methylcellulose were incubated for 7 days at $37^{\circ} \mathrm{C}, 5 \% \mathrm{CO}_{2}$, and $2 \% \mathrm{O}_{2}$. After incubation, the cells grown on poly-HEMA dishes were centrifuged at $300 \mathrm{~g}$ for 5 min at $4{ }^{\circ} \mathrm{C}$, plated onto regular cell culture vessels and cultured at $37^{\circ} \mathrm{C}, 5 \% \mathrm{CO}_{2}$, and $2 \% \mathrm{O}_{2}$ in $\mathrm{FY}$ medium. Similarly, suspension of cells incubated in methylcellulose was diluted 1:5 with PBS (Gibco), centrifuged, plated and cultured. Cell growth was monitored using EVOS XL microscope. Colonies of cells were stained with $1 \%$ methylene blue in methanol (Sigma-Aldrich) and photographed.

\section{Cell invasion}

CR-NB cells were plated in 96-well ultra-low attachment round-bottom plate (Corning), $2 \times 10^{3}$ cells per well. The cells were subsequently embedded in Spheroid Formation Matrix (R\&D Systems) and incubated under hypoxic conditions ( $2 \%$ oxygen) for 4 days to allow for spheroid formation. Cancer spheroids were then immersed in Invasion Matrix (R\&D Systems) and monitored for cell invasion under an inverted microscope.

\section{Cell migration}

Cell motility was assessed using a transwell migration assay, as previously described [41]. CR-NB cells were plated onto BD FluoroBlok ${ }^{\mathrm{TM}}$ 96-well plates (BD Biosciences, San Jose, CA), $1 \times 10^{4}$ cells per well. Both upper and lower chambers contained FY medium with the same FBS concentration (5\%) to measure spontaneous cell migration. The cells were incubated for $22 \mathrm{~h}$ at $37^{\circ} \mathrm{C}, 5 \%$ $\mathrm{CO}_{2}$, and $2 \% \mathrm{O}_{2}$ and then stained with Calcein $\mathrm{AM}$ at concentration $4 \mu \mathrm{g} / \mathrm{ml}$ diluted in Hank's Balanced Salt Solution (HBSS, Thermo Fisher Scientific). Fluorescence intensity was measured from the bottom of the plate. 


\section{Results}

\section{Optimization of growth conditions for NB cells}

The original CR method involved culture of normal or cancer cells in $\mathrm{F}$ medium containing ROCK inhibitor, Y27632, in the presence of irradiated feeder cells-J2 mouse fibroblasts [21]. To identify the optimal growth conditions for NB cells, different combinations of the above factors were tested. Tumor tissues from TH-MYCN mice were processed and NB cells cultured under various conditions, using different substrate and media formulations, as shown in Table 1. The growth under normoxic conditions and in $2 \%$ oxygen was compared. Moreover, factors implicated in regulation of NB proliferation and differentiation, including BDNF, NPY and corticosterone, were tested [29-37]. Optimal growth was observed in cells cultured in CR F medium with Y-27632 compound (FY medium), in noncoated vessels, under hypoxic conditions $\left(37^{\circ} \mathrm{C}, 5 \% \mathrm{CO}_{2}\right.$, $2 \% \mathrm{O}_{2}$ ) (Table 1). No additional beneficial effect of the neurotrophic factors was observed in the presence of $\mathrm{Y}$ 27632, while corticosterone and $\mathrm{J} 2$ feeder cells inhibited NB cell growth. The continuous culture with the ROCK inhibitor was associated with a characteristic cytoskeleton remodeling manifested by a decrease in the number of peripheral actin fibers (Fig. 1a, b) [42, 43]. Using these cell culture conditions, NB cells were grown, passaged, as well as frozen and biobanked. No problems with subsequent culture of the cryopreserved cells were noted. Using this modified CR method, we generated 21 stable mouse NB cell lines (CR-NB). After optimizing conditions for tissue processing and cell culture, the success rate in generating cell lines from mouse NB specimens was $90 \%$. Viability of the established CR-NB cell lines was 90-95\%, with approximate doubling time of $64 \mathrm{~h}$ (Fig. 1c).

\section{CR-NB cells exhibit heterogenous phenotypes}

Generated NB cell lines demonstrated a unique phenotype (Fig. 2). Initially, the cells grew as non-adherent spheres and as a single cell suspension (Fig. 2a). Their viability at this stage was 40-44\%. After $\sim 2$ days, single cells started to attach, forming a monolayer of cells with mesenchymal phenotype-large, flat, elongated cells with large nuclei and strong attachment to the plate surface (Fig. 2b). Subsequently, small, round, nonelongated cells attached, either as spheres or single cells, and grew atop the already formed monolayer (Fig. 2b). This population of cells soon began to spread outward (Fig. 2c), and a number of them differentiated, as demonstrated by formation of neurospheres with neurite projections (Fig. 2d). In majority of established cell lines, both cell types, mesenchymal and neuronal, were
Fig. 1 Growth of CR-NB cells is associated with cytoskeleton remodeling. a Primary NB cells isolated from a tumor arising in TH-MYCN mice, cultured without ROCK inhibitor, stained with Alexa Fluor 488 phalloidin. b Phalloidin-stained CR-NB cell line developed from TH-MYCN tumor in the presence of ROCK inhibitor, Y-27632. Fluorescence microscopy, scale bar represents $100 \mu \mathrm{m}$. c Growth curve of primary CR-NB cells in optimized cell culture conditions: CR F medium + $10 \mu \mathrm{M}$ Y-27632 compound, noncoated vessels, $2 \%$ oxygen

\section{A $F$ medium}
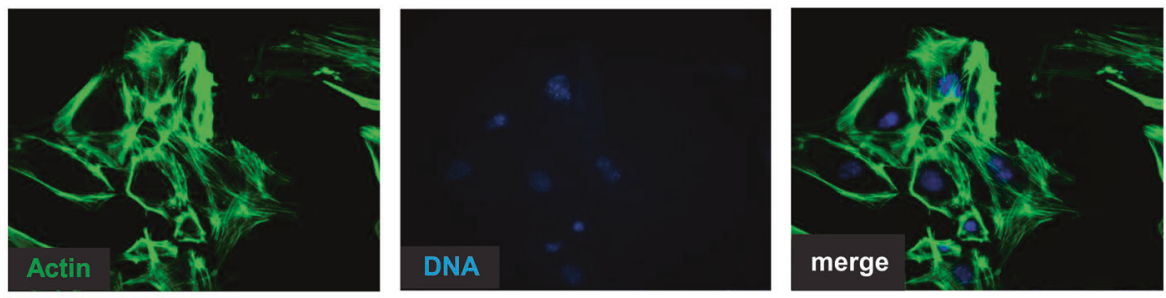

B FY medium
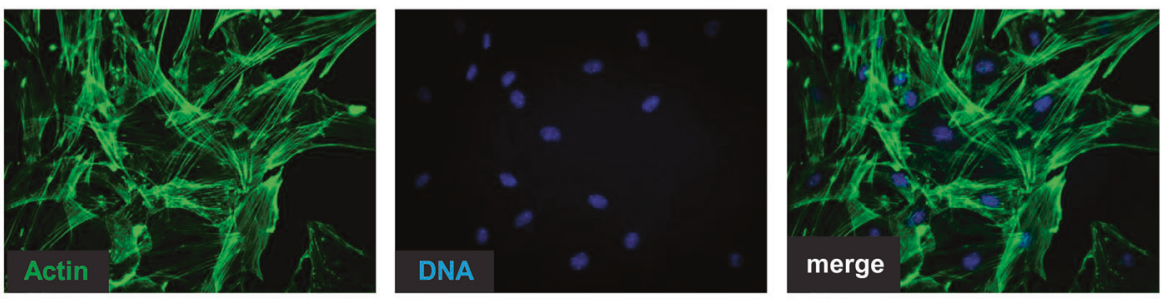

C

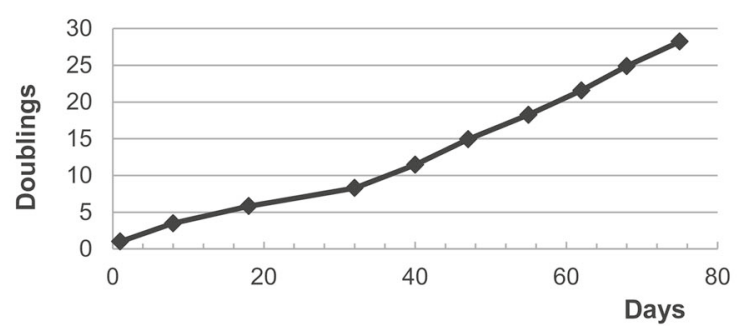


Fig. 2 Morphology of murine $\mathrm{NB}$ cell lines generated by CR. a Initial growth of NB cells in suspension. b Attachment and expansion of mesenchymal cells (white arrow) followed by attachment of neuronal cells to the mesenchymal monolayer (yellow arrow). c Expansion of neuronal cells atop mesenchymal cells. d Neurospheres of NB cells form neurite projections. e Abundant growth of both mesenchymal and adrenergic NB cells. f A CR-NB cell line consisting mostly of mesenchymal cell monolayer; single adrenergic cells are scarcely distributed between them. Phase contrast images, scale bars represent $400 \mu \mathrm{m}$. g The average proportion of mesenchymal cells vs. adrenergic cells (mean of $\%$ counted cells $\pm \mathrm{SD}$ )
A

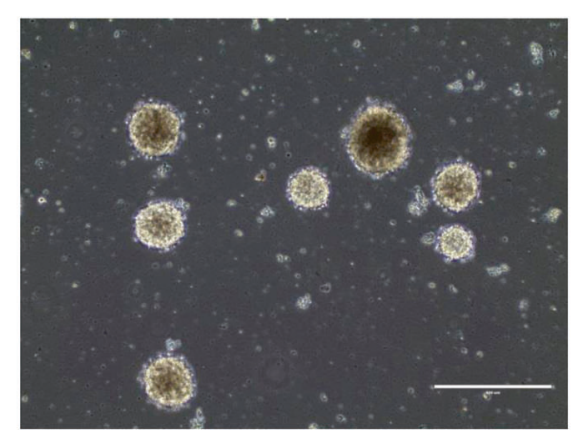

C

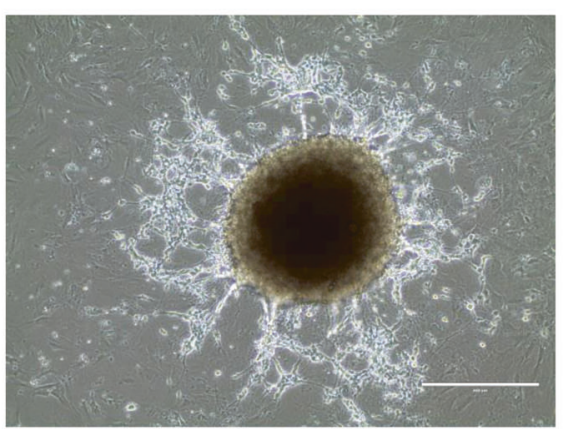

E

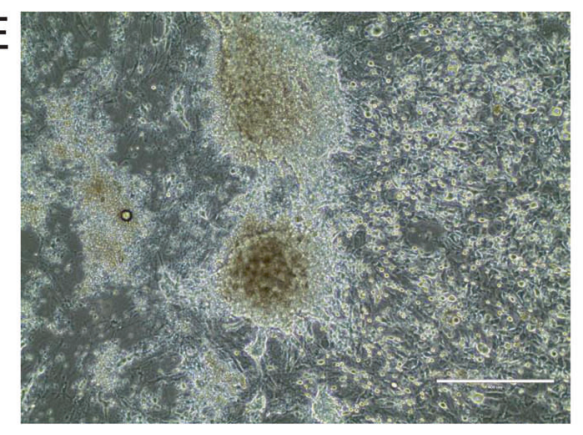

G

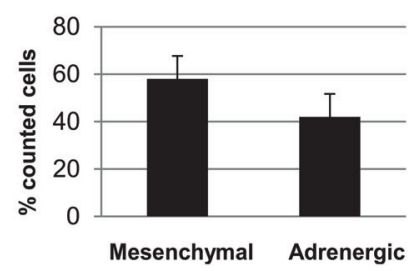

B

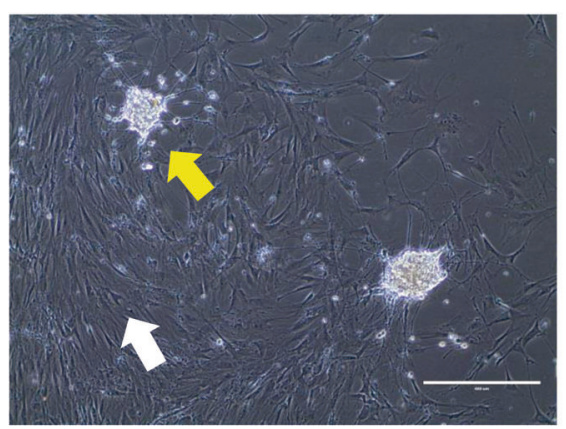

D

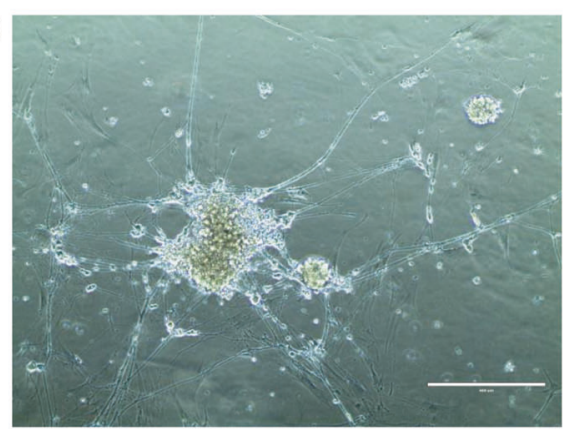

$\mathrm{F}$

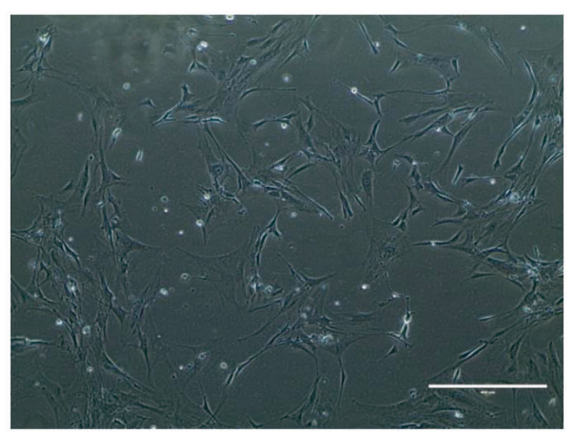

clearly visible during passages (Fig. 2e). One of the 21 established cell lines consisted mostly of mesenchymal cells, with a low number of single neuronal-type cells scarcely distributed between them (Fig. 2f). Based on the morphological criteria, the average proportion of mesenchymal cells and adrenergic cells was $58-42 \%$, respectively (Fig. 2g).

\section{All CR-NB cells express neuronal markers}

To confirm the neuroblastic origin of the CR cultures, the cells were tested for expression of known NB biomarkers by immunofluorescence. Despite their morphological differences, mesenchymal-like and neuronal cell populations shared features characteristic for NB. All cells in the culture were positive for a marker of peripheral neurons, peripherin (Fig. 3a), and a sympathetic lineage marker, Phox2B (Fig. 3b) [44]. No substantial presence of stromal cells negative for the above markers was observed in CR-NB cultures (Fig. 3).

\section{Two distinct populations of CR-NB cells vary in expression of mesenchymal and adrenergic markers}

Although both positive for neuronal markers, the populations of mesenchymal- and neuronal-like cells varied in expression of certain lineage-specific markers. The NB cells with neuronal phenotype expressed $\mathrm{TH}$ associated with 
Fig. 3 CR-NB cultures are positive for NB biomarkers. a Expression of peripherin, a marker of peripheral neurons, in CR-NB cells.

b Immunofluorescence detection of a sympathoadrenal marker, Phox 2B, in CR-NB cell line. Representative images are shown. Scale bars represent $100 \mu \mathrm{m}$

Fig. 4 Two distinct NB cell populations differentially express lineage-specific markers. a Adrenergic cells in neurospheres express tyrosine hydroxylase $(\mathrm{TH})$.

b Immunofluorescence detection of a sympathetic neurotransmitter, neuropeptide $\mathrm{Y}$ (NPY) in NB cells with neuronal phenotype.

c Immunodetection of vimentin in mesenchymal NB cells. Representative images are shown. Scale bar represents $100 \mu \mathrm{m}$
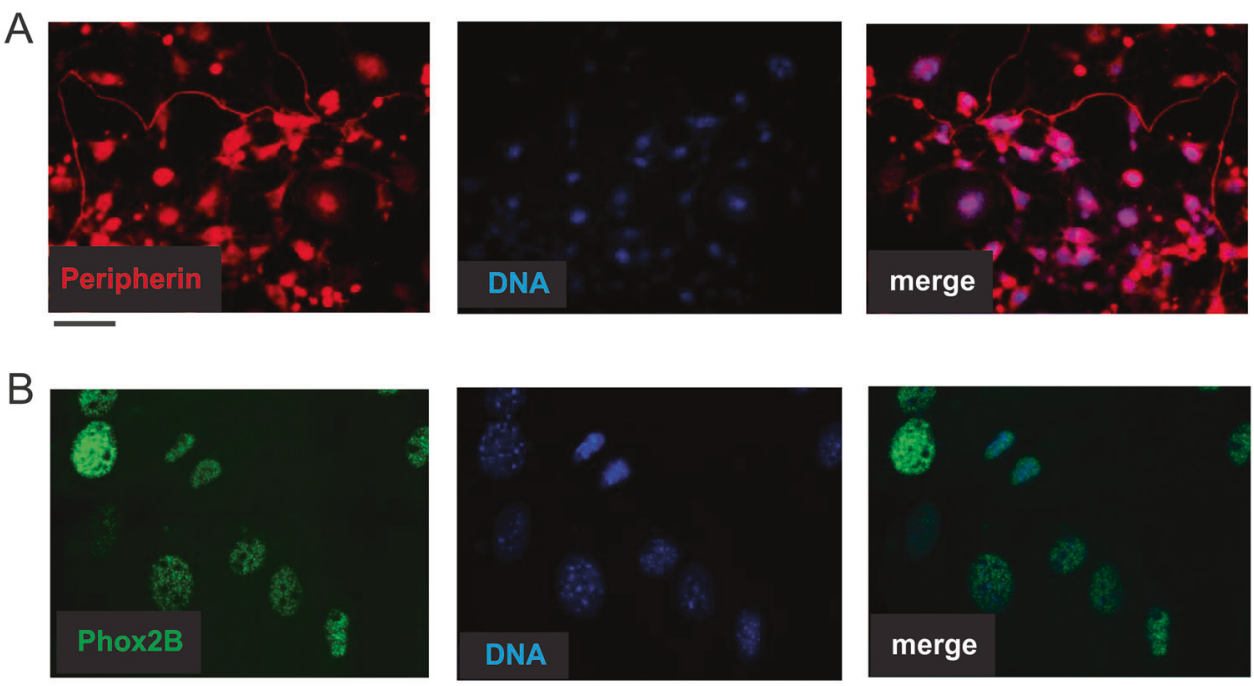

A
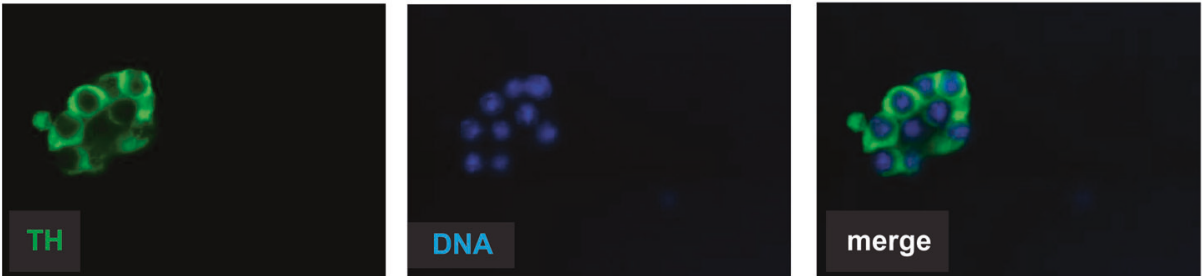

B
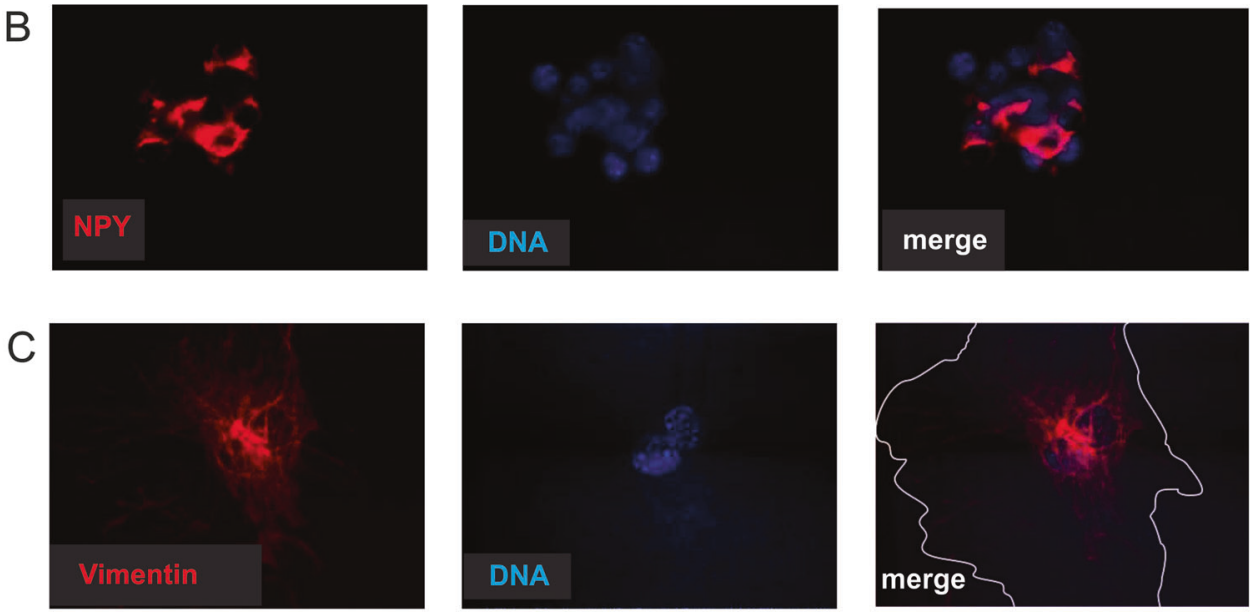

adrenergic phenotype and a sympathetic neurotransmitter, NPY (Fig. 4a, b). The cells with fibroblast-like morphology were negative for these markers, yet expressed a mesenchymal marker, vimentin (Fig. 4c). Consistent with this observation, the CR-NB cell lines with the neuronal component had an ability to release NPY, as the peptide was detectable in their conditioned media by ELISA (average concentration of $0.25 \mathrm{ng} / \mathrm{ml}$ ). In contrast, NPY was not measurable in the conditioned media from the predominantly mesenchymal CR-NB cell line shown in Fig. $2 \mathrm{f}$. Quantitative analysis of the cells stained with adrenergic and mesenchymal markers confirmed the ratio between these two cell types calculated based on the morphological criteria (Fig. 2g).

In addition to the lineage-specific markers, there was a subset of proteins expressed in both cell populations, albeit varying in intensity of the staining and their subcellular localization. Expression of a NB marker, ganglioside GD2, was more profound in adrenergic cells, as compared with the mesenchymal cell population (Fig. 5a) [45]. Similarly, positive staining for NPY receptor, NPY5R, was observed in both NB cell types, although with distinct patterns- 
Fig. 5 Mesenchymal and adrenergic CR-NB cells vary in cellular localization and pattern of specific markers.

a Localization of ganglioside GD2 in mesenchymal (white arrow) and adrenergic (yellow arrow) NB cells detected by immunofluorescence in CR-NB cells. b Immunofluorescence staining revealed NPY5R fiberlike pattern in mesenchymal cells (white arrow) and its diffused perinuclear localization in adrenergic cells (yellow arrow). c Costaining with antiNPY5R antibody and phalloidin in mesenchymal CR-NB cells. Scale bars represent $100 \mu \mathrm{m}$
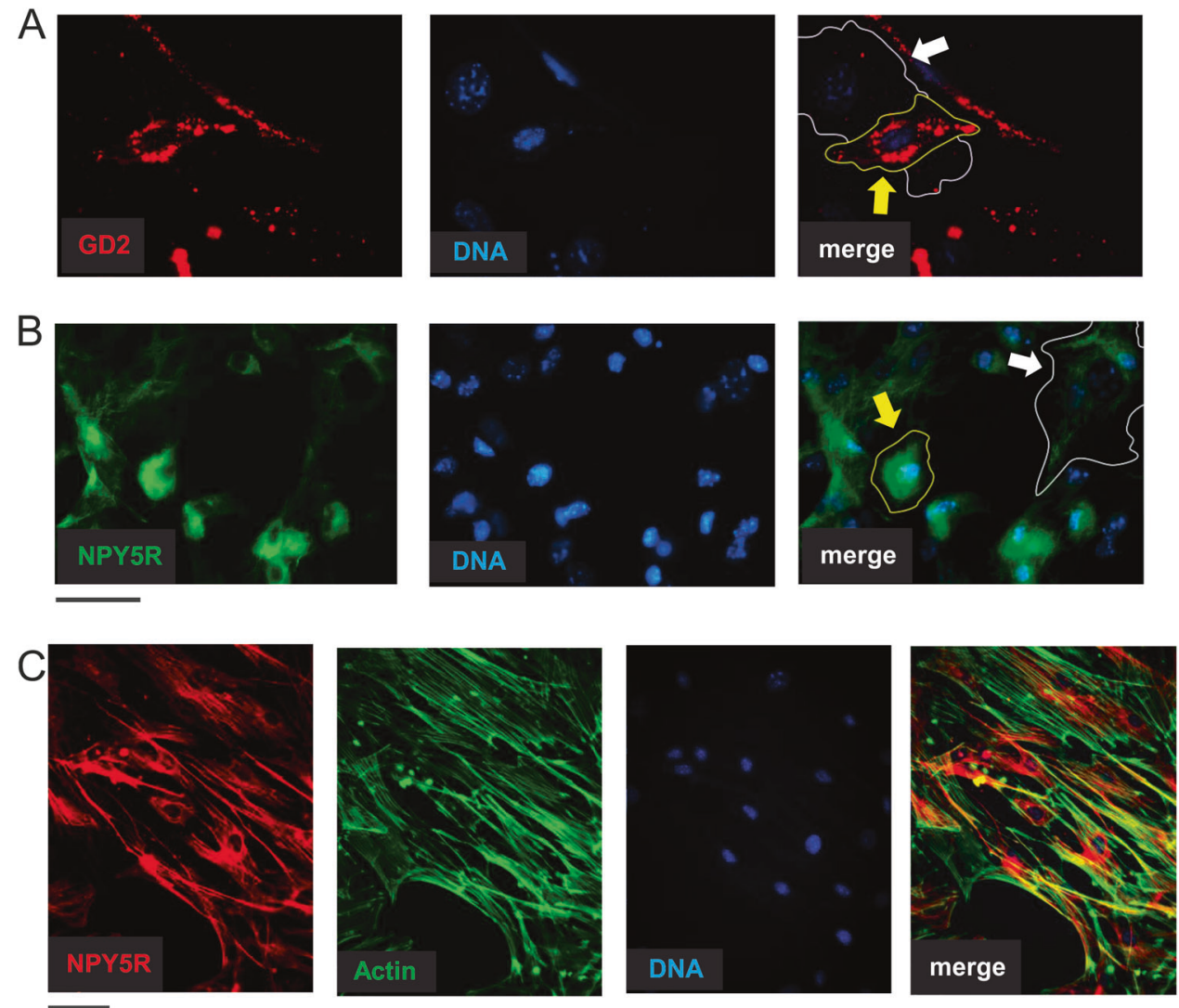

diffused in adrenergic cells and fiber-like in mesenchymal cells (Fig. 5b). Costaining with phalloidin revealed frequent localization of the NPY5R along F-actin fibers in mesenchymal cell type, suggesting its association with cytoskeleton regulation (Fig. 5c).

\section{The heterogeneity of CR-NB cell cultures recapitulates NB cell diversity in tumor tissues}

To validate our model, we compared expression of the markers expressed in CR-NB cells and in tumor tissues derived from TH-MYCN mice. The NB tumors from this animal model exhibited a highly undifferentiated phenotype with very low stromal content (Fig. 6a). All NB cells were uniformly positive for a marker of sympathoadrenal differentiation, Phox2B (Fig. 6b). In contrast, expression of sympathetic markers-TH and NPY — varied between cell populations, as tumor tissues contained cells positive, negative or weakly positive for these proteins (Fig. 6c, d). Although all NB cells were positive for NPY5R, its expression was elevated in cells surrounding blood vessels, suggesting association with an angioinvasive phenotype (Fig. 6e, f). The mesenchymal marker, vimentin, was expressed in a small population of the tumor cells forming colonies within the tumor tissue (Fig. 6g).

\section{CR-NB cells retain anchorage-independent growth capability}

The tumorigenicity of generated CR-NB cell lines was verified by anchorage-independent growth assays. The cells were plated onto low attachment poly-HEMA plates or into tubes with methylcellulose and incubated for 7 days. Within that time, the growth of spheroids was observed on polyHEMA plates (Fig. 7a, b). Following a week of anchorageindependent culture either on poly-HEMA plates or in methylcellulose, CR-NB cells were plated back onto regular cell culture dishes and maintained until reaching confluence, as visualized in methylene blue stained cell culture vessels (Fig. 7c-f). Throughout this procedure, the cells remained viable, grew rapidly, and were passaged and frozen afterwards.

\section{CR-NB cells exhibit invasiveness and motility}

Invasiveness of the newly generated CR-NB cell lines was evaluated using a spheroid invasion assay. CR-NB cells invaded the matrix composed of extracellular matrix proteins within 4 days from embedding (Fig. $7 \mathrm{~g}$ ). Both tested CR-NB cell lines also showed a significant motility in a transwell migration assay (Fig. 7h). 
H\&E

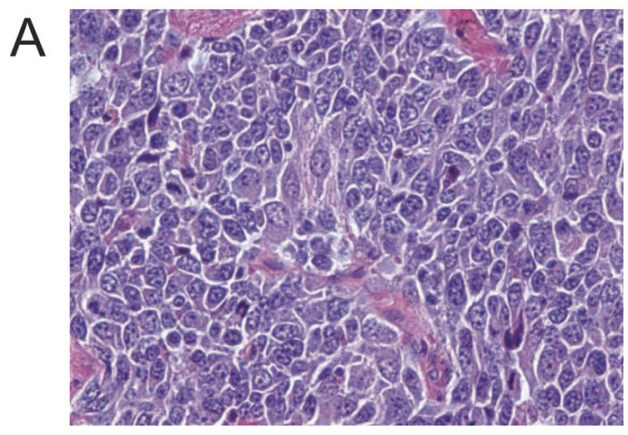

TH
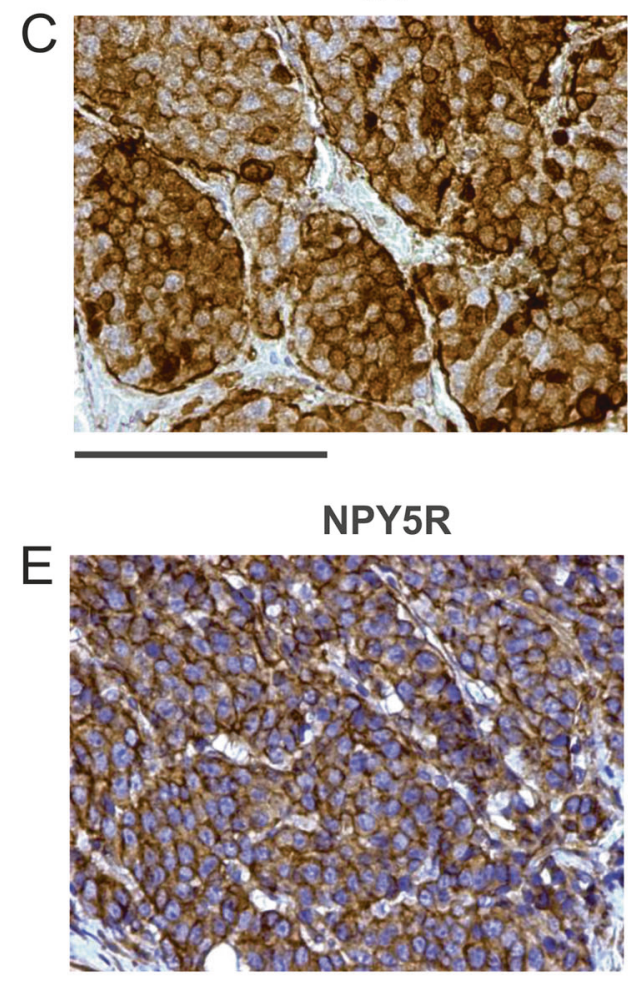

Vimentin

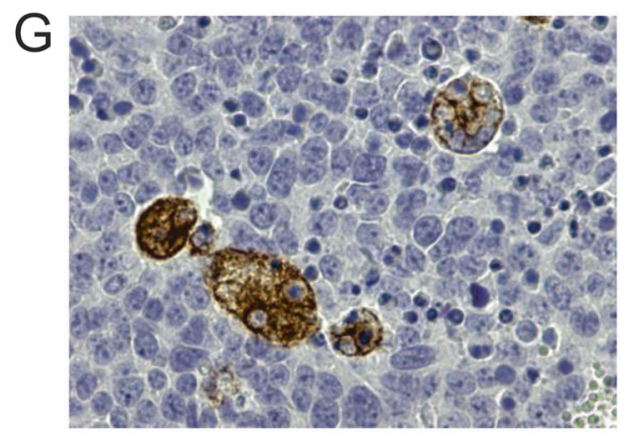

Fig. 6 Heterogeneous phenotype of NB cells in tumor tissues from THMYCN mice. a Hematoxylin-eosin (H\&E) staining of tumor tissue. b Uniform expression of the NB marker, Phox2B, in TH-MYCN tumor tissue. $\mathbf{c}, \mathbf{d}$ Heterogeneous expression of the adrenergic marker, tyrosine hydroxylase $(\mathrm{TH})(\mathrm{c})$ and a sympathetic neurotransmitter, neuropeptide

\section{Phox2B}

B
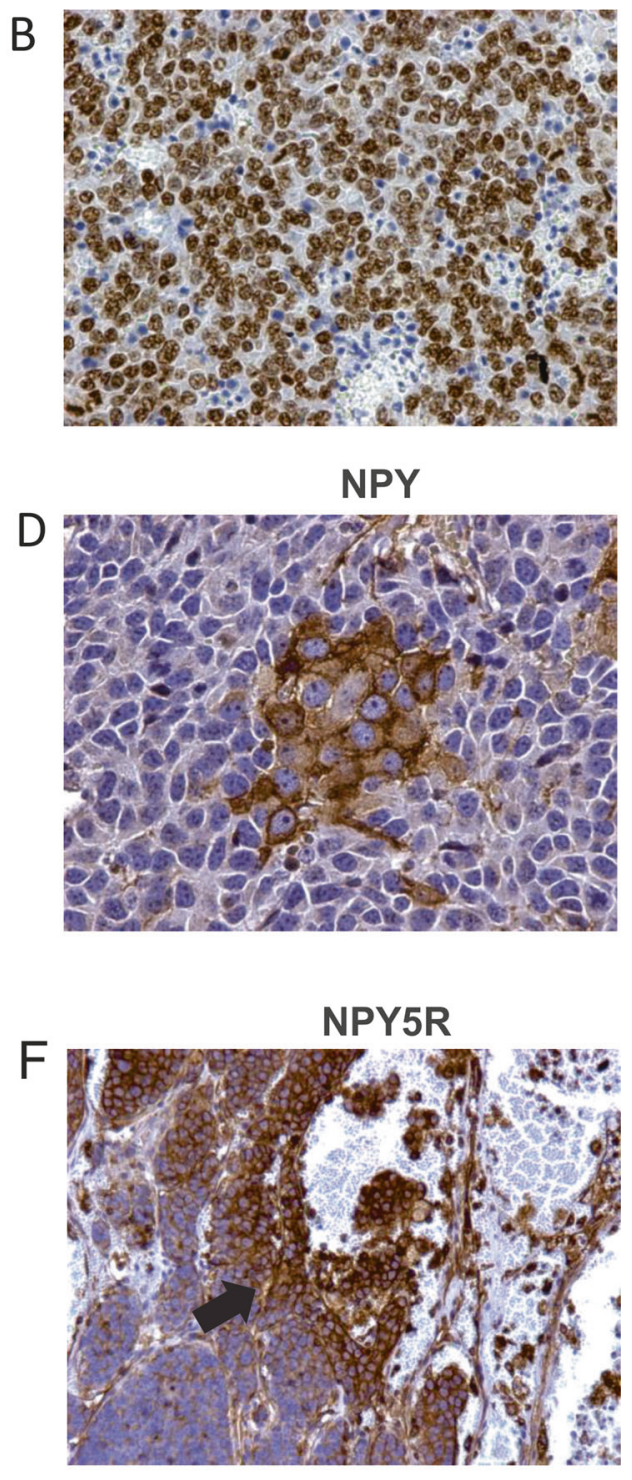

Y (NPY) (d). e, f Expression of the NPY receptor, NPY5R, in tumor tissue under high and low magnification reveals positive staining in all NB cells with higher intensity around blood vessels (arrow). g Heterogeneous expression of the mesenchymal marker, vimentin. Scale bars represent $100 \mu \mathrm{m}$ 
Fig. 7 Malignant features of CRNB cell lines. a-d Subsequent stages of the anchorageindependent growth of CR-NB cells on poly-HEMA low attachment plates. Cells grown in suspension on poly-HEMA plates for 7 days $(a, b)$ were plated into standard cell culture plates under established optimal culture conditions (c) and upon reaching confluency visualized by methylene blue staining (d). e, f Cells cultured for 7 days under anchorage-independent conditions in methylcellulose were plated into the standard culture plates and their growth assessed as above. Scale bars represent $400 \mu \mathrm{m}$. g CR-NB cells invade the extracellular matrix 4 days after embedding. Scale bar represents $200 \mu \mathrm{m}$. h CR-NB cell lines showed a significant motility in a transwell migration assay. Mean

fluorescence intensity \pm standard error is shown. $* * * p<0.001$ as compared with control (no cells)
Poly-HEMA plates
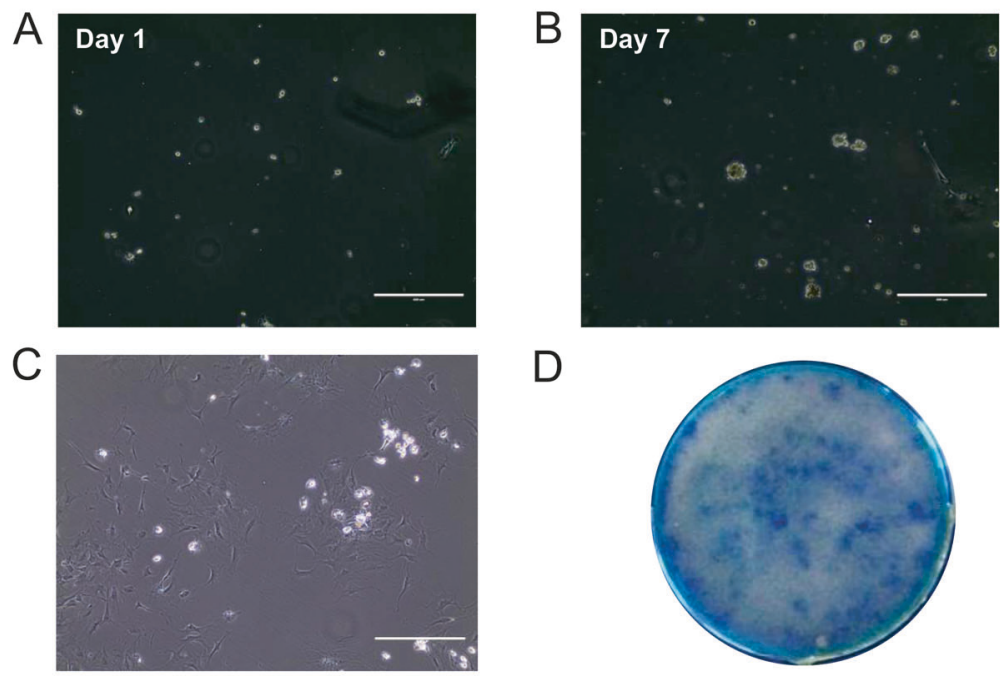

D

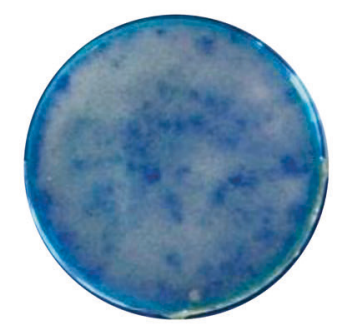

Methylcellulose assay

E

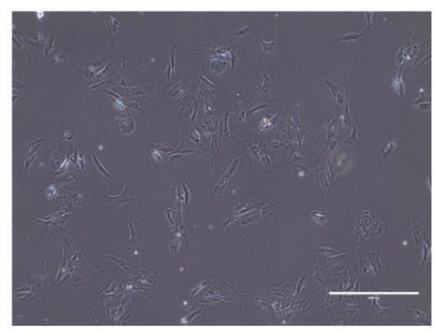

$\mathrm{F}$

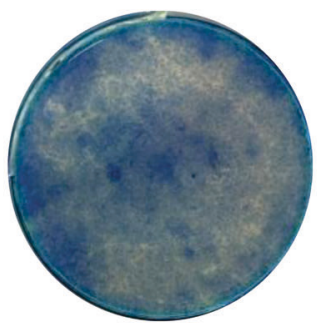

G

Invasion

$\mathrm{H}$

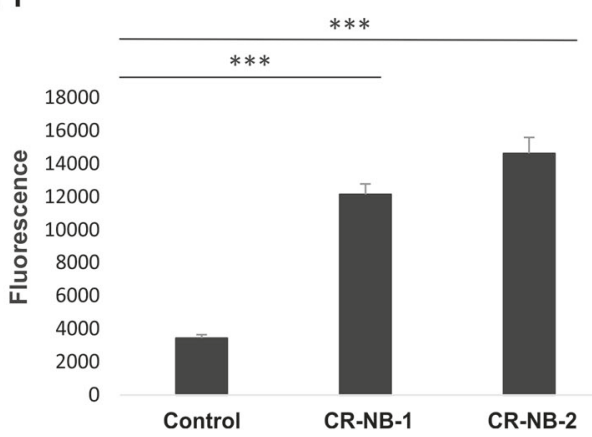

\section{Discussion}

Due to the disease heterogeneity and rarity, clinical trials on NB are particularly challenging, with many potential therapeutic targets to test in a limited population of pediatric patients [5]. These challenges underscore the importance of an appropriate prioritization of such trials based on reliable preclinical models. The existing established NB cell lines, although extensively utilized, do not fully represent the complexity of the disease [8]. Moreover continuous growth and passaging of such cell lines may contribute to accumulation of genetic and phenotypic changes, which alter their drug response [46]. On the other hand, patient-derived xenografts are sparse due to limited availability of the clinical material [9]. As in case of other animal models, their use is also time consuming and costly. Thus, here we propose $\mathrm{CR}$ technology for development of primary cultures from NB tumors, which may enable personalized tests of drug sensitivity.

Recent advances in patient-derived models give a unique opportunity to establish reliable models of various diseases. CR technology, one of the highly significant milestones in generation of these high-quality laboratory models, allows rapid propagation of cells obtained from patients [2123 , 26]. It relies on the use of ROCK inhibitor, Y-27632, typically in combination with feeder cells, to induce cell 
proliferation [21]. In normal cells, CR induces an adult stem-like state. The resulting cells retain the ability to terminally differentiate when removed from CR conditions [27]. In CR cultures from tumor tissues, phenotypic and genotypic features of the primary tumor are maintained [26, 28]. Importantly, CR tumor cells have been used to identify an appropriate therapy for a pediatric HPV-positive lung cancer and to identify both genetic and nongenetic alterations in lung tumors that correlate with patient's drug resistance pattern $[47,48]$. Overall, CR has been successful in generating several types of human tumor models and other human and mouse cell cultures used for various research purposes [49-54]. Therefore we anticipated that it could be useful for generating a valid patient-derived model for studying NB.

While using CR, it is necessary to optimize culture conditions and/or tissue processing to establish viable cell lines and increase proliferation rate of a particular cell type $[51,55]$. In this study, we modified both steps of the procedure by limiting enzymatic treatment during tissue preparation, excluding feeder cells and culturing cells in $2 \%$ oxygen. Similar modifications have been proven successful in establishing primary cell cultures from other tumor types, including pancreatic, colon, and neuroendocrine cervical cancer [21, 55]. Notably, J2 mouse fibroblasts that were previously used as feeder cells in other CR cultures inhibited growth of CR-NB cells. Instead, the mesenchymal-type NB cells appeared to play the role of feeders, as the adrenergic cells were attaching to the mesenchymal monolayer and their expansion was dependent on this process. The presence of distinct cell populations in CR-NB cultures supports previous findings indicating that $\mathrm{CR}$ results from reprogramming of the multilineage cell population rather than clonal selection and expansion of one cell subpopulation [27].

Our initial attempts to develop NB cell lines from tumors arising in TH-MYCN mice using traditional cell culture techniques (RPMI or DMEM media supplemented with $10 \%$ FBS, cultured under normoxic conditions) were hindered by profound neuronal differentiation of the NB cells. Despite initial growth, the isolated NB cells developed neuronal phenotype and cease to proliferate, which precluded their passaging (data not shown). The culture in $2 \%$ oxygen in the presence of the ROCK inhibitor, Y-27632, prevented this effect and promoted proliferation of CR-NB cells. Hypoxia is a known factor preventing NB differentiation, while ROCK inhibition has been shown to stimulate the proliferation of a variety of cells [56-59]. The growth stimulation triggered by Y-27632 compound was sufficient to replace the requirement for other factors known to promote NB survival and proliferation (BDNF and NPY) or prevent their neuronal differentiation (corticosterone) [29-37]. The proliferative effect of Y-27632 is associated with cytoskeleton remodeling due to the inhibition of the RhoA/ROCK pathway and appears to be involved its antiapoptotic activity [26, 60]. Similar phenomenon was observed in CR-NB cultures isolated in our study. Importantly, RhoA/ROCK axis is essential for regulation of neurite formation and function in NB cells, underlying the role of this pathway in biology of these tumors [42]. However, further studies are required to determine the role of the Y-27632-driven cytoskeleton remodeling in regulation of CR-NB cell differentiation and survival in vitro.

The presence of two cell populations observed in CR-NB cultures isolated from TH-MYCN mice has been previously described in established NB cell lines and primary cell cultures developed in neural stem cell medium [12-14]. In these cultures, the adrenergic cells expressed proteins characteristic for sympathetic neurons, while the less differentiated mesenchymal cells were positive for markers of this lineage [14]. Similarly, in CR-NB cultures, the cells with neuronal phenotype were positive for TH and NPY, while the cells with fibroblast-like morphology expressed vimentin. However, both cell types expressed neuronal and NB-specific markers-peripherin, GD2 and Phox2B, confirming their neuroblastic origin. While previous studies indicated that the marker of early sympathoadrenergic differentiation, Phox2B, was expressed mainly in the committed NB cells with neuronal features, one of the reported primary NB cultures exhibited its expression in both mesenchymal and adrenergic cell populations [14]. A similar expression pattern observed in our CR-NB cultures may reflect the transitional state of differentiation of mesenchymal NB cells. The fact that mesenchymal cells appear first in cell culture indicates that adrenergic cells may develop via transdifferentiation of the mesenchymal cells, with Phox2B expression representing the first step in this process [14]. This hypothesis is further supported by the fact that the neuronal cells appeared to be dependent in their growth and survival on the mesenchymal cells, since our attempts to culture them separately were unsuccessful. In contrast, one of the isolated CR-NB lines consisted almost exclusively of the mesenchymal NB cells. Further studies are required to determine if these mesenchymal cells serve as a cancer stem cell population in NB.

The histopathological analysis of TH-MYCN tumor tissues confirmed that the CR-NB primary cultures accurately recapitulate cell phenotypes and heterogeneity observed in vivo. Tumors arising in this animal model mimic the most aggressive, MYCN-amplified NBs [15-17]. Consequently, these tumors are undifferentiated and stroma-poor. In line with this, the CR-NB cultures consisted mostly of a pure population of tumor cells, without cells negative for NB markers detectable by immunostaining. However, CR technology is capable of simultaneous propagation of both normal and tumor cells from cancer specimens [21]. Thus, if 
more differentiated tumor types with marked stromal content are used, it is plausible that both components will be present. Such CR-NB cultures would be indispensable to investigate the role of tumor environment, such as interactions between NB and Schwann cells [61-63]. These heterogeneous cultures may also represent more reliable model for drug testing.

Similar to the CR-NB cultures, all tumor cells in THMYCN NB tissues were positive for Phox2B, while expression of sympathetic markers, TH and NPY, and a mesenchymal protein, vimentin, was heterogeneous. The pattern of vimentin expression within the tumor tissue was consistent with previous reports indicating the presence of scarce mesenchymal cells in NB tumors [14]. Interestingly, expression of NPY5R, although detectable in all NB cells, was the most profound in tumor cells surrounding blood vessels. This association of high NPY5R levels with an angioinvasive phenotype of $\mathrm{NB}$ cells was previously described by us in human NB tissues [40]. In line with this, in CR-NB cultures, NPY5R was expressed in both cell populations, yet only in mesenchymal cells its subcellular distribution aligned with F-actin fibers. As the mesenchymal NB cells have been implicated in NB migratory phenotype, these findings are consistent with potential role of NPY5R in the metastatic phenotype of NB mediated by cytoskeleton regulation $[12,40]$. Hence, this data further support the notion that CR-NB primary cultures accurately preserve the tumor cell heterogeneity observed in vivo. Importantly, the NB cells isolated in this study retained their ability to grow under anchorage-independent conditionsthe hallmark feature used to test tumorigenic potential of cells [64]. Further studies are required to determine if the CR-NB cell lines are suitable for xenografting in animal models, as described for CR cells derived from other tumor types [26].

To our knowledge, our study is the first to generate durable NB cell lines using CR technology. While the murine cells isolated in our study will be a valuable tool for basic and preclinical research, the next important step is to determine utility of CR method to establish human NB cell lines. Previous studies demonstrated equal efficiency of the $\mathrm{CR}$ in establishing human and rodent cell cultures [26, 49, 51]. Importantly, such CR cultures can be established from small amount of the initial material, potentially also needle biopsies [21, 26]. Since recent data clearly indicate that the recurring NB tumors vary significantly from the initial primary lesions in their molecular profiles, there is a growing understanding of the need for additional testing during the disease progression; the approach thus far not utilized in the routine NB care [5-7]. Thus, if the described optimization of CR technique is proven successful for generating viable cell lines from patients, it will be highly beneficial for establishing valid patient-derived models. Due to their robust growth and accurate replication of the original tumor phenotype, such human CR-NB cells could become a novel model for investigations into NB biology and personalized drug testing.

Acknowledgements This work was supported by National Institutes of Health (NIH) grants: 1RO1CA123211, 1R03CA178809, R01CA197964, and 1R21CA198698, as well as grants from Sunbeam Foundation and Children's Cancer Foundation to JK. The study was performed in collaboration with the Georgetown Lombardi Comprehensive Cancer Center's Tissue Culture and Biobanking Shared Resource (TCBSR) and the Histopathology and Tissue Shared Resource (HTSR), both supported by NIH/NCI grant P30-CA051008. In addition, Georgetown University Department of Pathology Research Funds were used to support these studies.

\section{Compliance with ethical standards}

Conflict of interest The authors declare that they have no conflict of interest.

Publisher's note: Springer Nature remains neutral with regard to jurisdictional claims in published maps and institutional affiliations.

\section{References}

1. Maris JM. Recent advances in neuroblastoma. N Engl J Med. 2010;362:2202-11.

2. Matthay KK, Maris JM, Schleiermacher G, Nakagawara A, Mackall CL, Diller L, et al. Neuroblastoma. Nat Rev Dis Primers. 2016;2:16078.

3. Brodeur GM. Neuroblastoma: biological insights into a clinical enigma. Nat Rev Cancer. 2003;3:203-16.

4. Cheung NK, Dyer MA. Neuroblastoma: developmental biology, cancer genomics and immunotherapy. Nat Rev Cancer. 2013;13:397-411.

5. Fletcher JI, Ziegler DS, Trahair TN, Marshall GM, Haber M, Norris MD. Too many targets, not enough patients: rethinking neuroblastoma clinical trials. Nat Rev Cancer. 2018;18:389-400.

6. Abbasi MR, Rifatbegovic F, Brunner C, Mann G, Ziegler A, Potschger U, et al. Impact of disseminated neuroblastoma cells on the identification of the relapse-seeding clone. Clin Cancer Res. 2015;23:4224-32.

7. Eleveld TF, Oldridge DA, Bernard V, Koster J, Colmet Daage L, Diskin SJ, et al. Relapsed neuroblastomas show frequent RASMAPK pathway mutations. Nat Genet. 2015;47:864-71.

8. Teitz T, Stanke JJ, Federico S, Bradley CL, Brennan R, Zhang J, et al. Preclinical models for neuroblastoma: establishing a baseline for treatment. PLoS ONE. 2011;6:e19133.

9. Braekeveldt N, Wigerup C, Gisselsson D, Mohlin S, Merselius M, Beckman S, et al. Neuroblastoma patient-derived orthotopic xenografts retain metastatic patterns and geno- and phenotypes of patient tumours. Int J Cancer. 2015;136:E252-61.

10. Kamb A. What's wrong with our cancer models? Nat Rev Drug Discov. 2005;4:161-5.

11. Wilding JL, Bodmer WF. Cancer cell lines for drug discovery and development. Cancer Res. 2014;74:2377-84.

12. van Nes J, Chan A, van Groningen T, van Sluis P, Koster J, Versteeg R. A NOTCH3 transcriptional module induces cell motility in neuroblastoma. Clin Cancer Res. 2013;19:3485-94.

13. Bate-Eya LT, Ebus ME, Koster J, den Hartog IJ, Zwijnenburg DA, Schild L, et al. Newly-derived neuroblastoma cell lines 
propagated in serum-free media recapitulate the genotype and phenotype of primary neuroblastoma tumours. Eur J Cancer. 2014;50:628-37.

14. van Groningen $\mathrm{T}$, Koster J, Valentijn LJ, Zwijnenburg DA, Akogul N, Hasselt NE, et al. Neuroblastoma is composed of two super-enhancer-associated differentiation states. Nat Genet. 2017;49:1261-6.

15. Weiss WA, Aldape K, Mohapatra G, Feuerstein BG, Bishop JM. Targeted expression of MYCN causes neuroblastoma in transgenic mice. EMBO J. 1997;16:2985-95.

16. Alam G, Cui H, Shi H, Yang L, Ding J, Mao L, et al. MYCN promotes the expansion of Phox2B-positive neuronal progenitors to drive neuroblastoma development. Am J Pathol. 2009; 175:856-66.

17. Hansford LM, Thomas WD, Keating JM, Burkhart CA, Peaston AE, Norris MD, et al. Mechanisms of embryonal tumor initiation: distinct roles for $\mathrm{MycN}$ expression and MYCN amplification. Proc Natl Acad Sci USA. 2004;101:12664-9.

18. Moore HC, Wood KM, Jackson MS, Lastowska MA, Hall D, Imrie $\mathrm{H}$, et al. Histological profile of tumours from MYCN transgenic mice. J Clin Pathol. 2008;61:1098-103.

19. Weiss WA, Godfrey T, Francisco C, Bishop JM. Genome-wide screen for allelic imbalance in a mouse model for neuroblastoma. Cancer Res. 2000;60:2483-7.

20. Terrile M, Bryan K, Vaughan L, Hallsworth A, Webber H, Chesler L, et al. miRNA expression profiling of the murine $\mathrm{TH}-$ MYCN neuroblastoma model reveals similarities with human tumors and identifies novel candidate miRNAs. PLoS ONE. 2011;6:e28356.

21. Liu X, Krawczyk E, Suprynowicz FA, Palechor-Ceron N, Yuan $\mathrm{H}$, Dakic A, et al. Conditional reprogramming and long-term expansion of normal and tumor cells from human biospecimens. Nat Protoc. 2017;12:439-51.

22. Sharifnia T, Hong AL, Painter CA, Boehm JS. EmergIng Opportunities for Target Discovery in Rare Cancers. Cell Chem Biol. 2017;24:1075-91.

23. Boehm JS, Golub TR. An ecosystem of cancer cell line factories to support a cancer dependency map. Nat Rev Genet. 2015;16:373-4.

24. Senft D, Leiserson MDM, Ruppin E, Ronai ZA. Precision oncology: the road ahead. Trends Mol Med. 2017;23:874-98.

25. Williams SP, McDermott U. The pursuit of therapeutic biomarkers with high-throughput cancer cell drug screens. Cell Chem Biol. 2017;24:1066-74.

26. Liu X, Ory V, Chapman S, Yuan H, Albanese C, Kallakury B, et al. ROCK inhibitor and feeder cells induce the conditional reprogramming of epithelial cells. Am J Pathol. 2012;180: 599-607.

27. Suprynowicz FA, Upadhyay G, Krawczyk E, Kramer SC, Hebert JD, Liu X, et al. Conditionally reprogrammed cells represent a stem-like state of adult epithelial cells. Proc Natl Acad Sci USA. 2012;109:20035-40.

28. Mahajan AS, Sugita BM, Duttargi AN, Saenz F, Krawczyk E, McCutcheon JN, et al. Genomic comparison of early-passage conditionally reprogrammed breast cancer cells to their corresponding primary tumors. PLoS ONE. 2017;12:e0186190.

29. Ho R, Eggert A, Hishiki T, Minturn JE, Ikegaki N, Foster P, et al. Resistance to chemotherapy mediated by TrkB in neuroblastomas. Cancer Res. 2002;62:6462-6.

30. Jaboin J, Kim CJ, Kaplan DR, Thiele CJ. Brain-derived neurotrophic factor activation of TrkB protects neuroblastoma cells from chemotherapy-induced apoptosis via phosphatidylinositol 3'-kinase pathway. Cancer Res. 2002;62:6756-63.

31. Li Z, Zhang J, Liu Z, Woo CW, Thiele CJ. Downregulation of Bim by brain-derived neurotrophic factor activation of TrkB protects neuroblastoma cells from paclitaxel but not etoposide or cisplatin-induced cell death. Cell Death Differ. 2007;14:318-26.

32. Jaboin J, Hong A, Kim CJ, Thiele CJ. Cisplatin-induced cytotoxicity is blocked by brain-derived neurotrophic factor activation of TrkB signal transduction path in neuroblastoma. Cancer Lett. 2003;193:109-14.

33. Czarnecka M, Trinh E, Lu C, Kuan-Celarier A, Galli S, Hong SH, et al. Neuropeptide Y receptor Y5 as an inducible pro-survival factor in neuroblastoma: implications for tumor chemoresistance. Oncogene. 2015;34:3131-43.

34. Kitlinska J. Neuropeptide Y (NPY) in neuroblastoma: effect on growth and vascularization. Peptides. 2007;28:405-12.

35. Kitlinska J, Abe K, Kuo L, Pons J, Yu M, Li L, et al. Differential effects of neuropeptide $\mathrm{Y}$ on the growth and vascularization of neural crest-derived tumors. Cancer Res. 2005;65:1719-28.

36. Yaniv SP, Ben-Shachar D, Klein E. Norepinephrineglucocorticoids interaction does not annul the opposite effects of the individual treatments on cellular plasticity in neuroblastoma cells. Eur J Pharmacol. 2008;596:14-24.

37. Lu C, Everhart L, Tilan J, Kuo L, Sun CC, Munivenkatappa RB, et al. Neuropeptide $\mathrm{Y}$ and its $\mathrm{Y} 2$ receptor: potential targets in neuroblastoma therapy. Oncogene. 2010;29:5630-42.

38. Krawczyk E, Suprynowicz FA, Sudarshan SR, Schlegel R. Membrane orientation of the human papillomavirus type 16 E5 oncoprotein. J Virol. 2010;84:1696-703.

39. Tilan JU, Krailo M, Barkauskas DA, Galli S, Mtaweh H, Long J, et al. Systemic levels of neuropeptide Y and dipeptidyl peptidase activity in patients with Ewing sarcoma-Associations with tumor phenotype and survival. Cancer. 2015;121:697-707.

40. Galli S, Naranjo A, Van Ryn C, Tilan JU, Trinh E, Yang C, et al. Neuropeptide $\mathrm{Y}$ as a biomarker and therapeutic target for neuroblastoma. Am J Pathol. 2016;186:3040-53.

41. Tilan JU, Lu C, Galli S, Izycka-Swieszewska E, Earnest JP, Shabbir A, et al. Hypoxia shifts activity of neuropeptide $\mathrm{Y}$ in Ewing sarcoma from growth-inhibitory to growth-promoting effects. Oncotarget. 2013;4:2487-501.

42. Maekawa M, Ishizaki T, Boku S, Watanabe N, Fujita A, Iwamatsu A, et al. Signaling from Rho to the actin cytoskeleton through protein kinases ROCK and LIM-kinase. Science. 1999;285:895-8.

43. McHardy LM, Warabi K, Andersen RJ, Roskelley CD. Roberge M. Strongylophorine-26, a Rho-dependent inhibitor of tumor cell invasion that reduces actin stress fibers and induces nonpolarized lamellipodial extensions. Mol Cancer Ther. 2005;4:772-8.

44. Mizuseki K, Sakamoto T, Watanabe K, Muguruma K, Ikeya M, Nishiyama A, et al. Generation of neural crest-derived peripheral neurons and floor plate cells from mouse and primate embryonic stem cells. Proc Natl Acad Sci USA. 2003;100:5828-33.

45. Terzic T, Cordeau M, Herblot S, Teira P, Cournoyer S, Beaunoyer $\mathrm{M}$, et al. Expression of disialoganglioside (GD2) in neuroblastic tumors: a prognostic value for patients treated with anti-GD2 immunotherapy. Pediatr Dev Pathol. 2018;21:355-62.

46. Ben-David U, Siranosian B, Ha G, Tang H, Oren Y, Hinohara K, et al. Genetic and transcriptional evolution alters cancer cell line drug response. Nature. 2018;560:325-30.

47. Yuan H, Myers S, Wang J, Zhou D, Woo JA, Kallakury B, et al. Use of reprogrammed cells to identify therapy for respiratory papillomatosis. N Engl J Med. 2012;367:1220-7.

48. Hata AN, Niederst MJ, Archibald HL, Gomez-Caraballo M, Siddiqui FM, Mulvey HE, et al. Tumor cells can follow distinct evolutionary paths to become resistant to epidermal growth factor receptor inhibition. Nat Med. 2016;22:262-9.

49. Timofeeva OA, Palechor-Ceron N, Li G, Yuan H, Krawczyk E, Zhong $\mathrm{X}$, et al. Conditionally reprogrammed normal and primary tumor prostate epithelial cells: a novel patient-derived cell model for studies of human prostate cancer. Oncotarget. 2016;8: 22741-58. 
50. Zhang Z, Bai Q, Chen Y, Ye L, Wu X, Long X, et al. Conditionally reprogrammed human normal bronchial epithelial cells express comparable levels of cytochromes p450 and are sensitive to $\mathrm{BaP}$ induction. Biochem Biophys Res Commun. 2018;503: 2132-8.

51. Moorefield EC, Blue RE, Quinney NL, Gentzsch M, Ding S. Generation of renewable mouse intestinal epithelial cell monolayers and organoids for functional analyses. BMC Cell Biol. 2018;19:15.

52. Butler CR, Hynds RE, Gowers KH, Lee Ddo H, Brown JM, Crowley C, et al. Rapid expansion of human epithelial stem cells suitable for airway tissue engineering. Am J Respir Crit Care Med. 2016;194:156-68.

53. Imai-Matsushima A, Martin-Sancho L, Karlas A, Imai S, Zoranovic $\mathrm{T}$, Hocke AC, et al. Long-term culture of distal airway epithelial cells allows differentiation towards alveolar epithelial cells suited for influenza virus studies. EBioMedicine. 2018;33:230-41.

54. Saeed K, Rahkama V, Eldfors S, Bychkov D, Mpindi JP, Yadav $\mathrm{B}$, et al. Comprehensive drug testing of patient-derived conditionally reprogrammed cells from castration-resistant prostate cancer. Eur Urol. 2017;71:319-27.

55. Yuan H, Krawczyk E, Blancato J, Albanese C, Zhou D, Wang N, et al. HPV positive neuroendocrine cervical cancer cells are dependent on Myc but not E6/E7 viral oncogenes. Sci Rep. 2017;7:45617.

56. Edsjo A, Holmquist L, Pahlman S. Neuroblastoma as an experimental model for neuronal differentiation and hypoxia-induced tumor cell dedifferentiation. Semin Cancer Biol. 2007;17:248-56.
57. Jogi A, Ora I, Nilsson H, Poellinger L, Axelson H, Pahlman S. Hypoxia-induced dedifferentiation in neuroblastoma cells. Cancer Lett. 2003;197:145-50.

58. Chapman S, Liu X, Meyers C, Schlegel R, McBride AA. Human keratinocytes are efficiently immortalized by a Rho kinase inhibitor. J Clin Invest. 2010;120:2619-26.

59. Piltti J, Varjosalo M, Qu C, Hayrinen J, Lammi MJ. Rho-kinase inhibitor Y-27632 increases cellular proliferation and migration in human foreskin fibroblast cells. Proteomics. 2015;15:2953-65.

60. Dakic A, DiVito K, Fang S, Suprynowicz F, Gaur A, Li X, et al. ROCK inhibitor reduces Myc-induced apoptosis and mediates immortalization of human keratinocytes. Oncotarget. 2016;7:66740-53.

61. Huang D, Rutkowski JL, Brodeur GM, Chou PM, Kwiatkowski JL, Babbo A, et al. Schwann cell-conditioned medium inhibits angiogenesis. Cancer Res. 2000;60:5966-71.

62. Liu S, Tian Y, Chlenski A, Yang Q, Salwen HR, Cohn SL. 'Cross-talk' between Schwannian stroma and neuroblasts promotes neuroblastoma tumor differentiation and inhibits angiogenesis. Cancer Lett. 2005;228:125-31.

63. Liu S, Tian Y, Chlenski A, Yang Q, Zage P, Salwen HR, et al. Cross-talk between Schwann cells and neuroblasts influences the biology of neuroblastoma xenografts. Am J Pathol. 2005;166: 891-900.

64. Colburn NH, Bruegge WF, Bates JR, Gray RH, Rossen JD, Kelsey WH, et al. Correlation of anchorage-independent growth with tumorigenicity of chemically transformed mouse epidermal cells. Cancer Res. 1978;38:624-34. 